(2) Open Access Full Text Article

\title{
Prevalence and related factors of psychological distress among cancer inpatients using routine Distress Thermometer and Chinese Health Questionnaire screening
}

\author{
This article was published in the following Dove Press journal: \\ Neuropsychiatric Disease and Treatment \\ 25 October 2016 \\ Number of times this article has been viewed
}

\author{
Yu-Jie Chiou' \\ Nien-Mu Chiu' \\ Liang-Jen Wang ${ }^{2}$ \\ Shau-Hsuan $\mathrm{Li}^{3}$ \\ Chun-Yi Lee' \\ Ming-Kung Wu' \\ Chien-Chih Chen' \\ Yi-Shan Wu' \\ Yu Lee' \\ 'Department of Psychiatry, \\ ${ }^{2}$ Department of Child and Adolescent \\ Psychiatry, ${ }^{3}$ Department of \\ Hematology-Oncology, Kaohsiung \\ Chang Gung Memorial Hospital, \\ Chang Gung University College of \\ Medicine, Kaohsiung, Taiwan, Republic \\ of China
}

Background: Clinical practice guidelines suggest routine screening for distress among cancer patients for immediate early psychiatric care. However, previous studies focusing on routine screening for psychological distress among cancer inpatients in Taiwan are scant. Thus, the aim of this study was to evaluate the prevalence and related factors of psychological distress and mental illness among cancer inpatients in Taiwan.

Patients and methods: This study was conducted as a retrospective chart review in a general hospital in southern Taiwan. Cancer inpatients were regularly screened by nursing staff using the Distress Thermometer and the 12-item Chinese Health Questionnaire. Positive screening results on either instrument were followed by a non-commanded referral to psychiatrists for clinical psychiatric diagnosis and treatment.

Results: Of the 810 participants in this study, 179 (22.1\%) were recognized as having psychological distress. Younger age (odds ratio $[\mathrm{OR}]=1.82$ ), having head and neck cancer $(\mathrm{OR}=2.43)$, and having not received chemotherapy $(\mathrm{OR}=1.58)$ were significantly related to psychological distress. Among the 56 patients (31.3\%) with psychological distress who were referred to psychiatrists, the most common mental illness was adjustment disorder $(n=22,39.2 \%)$, followed by major depressive disorder $(n=13,23.2 \%)$, depressive disorder not otherwise specified $(n=6$, $10.7 \%)$, and anxiety disorder not otherwise specified ( $n=4,7.1 \%)$.

Conclusion: Our study indicated that cancer inpatients with psychological distress were more likely to be younger in age, have head and neck cancer, and have not received chemotherapy. The most common psychiatric disorder was adjustment disorder. Early detection of psychological distress and prompt psychiatric consultation and management are very important for cancer inpatients.

Keywords: psychological distress, cancer inpatients, prevalence, related factors, Distress Thermometer, Chinese Health Questionnaire

\section{Introduction}

Cancer-related distress was depicted as a "multifactorial unpleasant emotional experience of a psychological, social, and/or spiritual nature that may interfere with the ability to cope effectively with cancer, its physical symptoms, and its treatment" by the National Comprehensive Cancer Network (NCCN) of the US. ${ }^{1}$ Distress is related to a lower quality of life, ${ }^{2}$ treatment compliance and efficacy, ${ }^{3,4}$ higher mortality, ${ }^{5-7}$ and a higher risk of suicide. ${ }^{8,9}$ Therefore, clinicians should make efforts to promote patients' quality of life and decrease medical costs by alleviating patient distress. ${ }^{10,11}$

\footnotetext{
Correspondence: Yu Lee

Department of Psychiatry, Kaohsiung Chang Gung Memorial Hospital, Chang Gung University College of Medicine, 123, Dapi Road, Niaosong, Kaohsiung 8330I, Taiwan, Republic of China Tel $+886773|7| 23 \times 63 \mid 8$ Fax +88677326817

Email lyu722@cgmh.org.tw
} 
The NCCN clinical practice guidelines (NCCN guidelines) in oncology distress management have, since 1997, advocated routine screening for distress in cancer patients. ${ }^{1}$ Similar to the model of using pain for the 5th vital sign, the use of distress for the 6th vital sign was recommended in 2005. ${ }^{12}$

Several medical centers have recommended regular screenings on all cancer patients, as a component of routine cancer management. ${ }^{13}$ This type of routine cancer care underscores that all patients with distress should receive the appropriate treatment and that top quality psychosocial cancer management involves systematic reevaluation and follow-up. However, challenges to care persist, containing not only the underestimation of the demand for psychosocial care but also the likely related factors. Since a majority of traditional tools designed to screen depression and distress are time-consuming for routine utilization in clinical situations, uncomplicated verbal and visual analog tools, such as the Distress Thermometer (DT),${ }^{14}$ the emotions thermometer, ${ }^{15}$ and the 12 -item General Health Questionnaire, ${ }^{16}$ have been recommended. Of these scales, DT is probably the most widely utilized. ${ }^{17-20}$

Although several investigations on cancer patients with psychological distress have been published, there are very few investigations on the related factors of distress and its prevalence in Taiwanese patients. The prevalence of psychological distress as screened by the DT was $56.5 \%$ and $28.8 \%$, respectively, according to Shim et al and Kim et al..$^{21,22}$ However, study limitations, including low response rates and scanty sample sizes, rendered generalization of the results to all cancer patients difficult. But with the increasing demands for treating distress in cancer patients, numerous hospitals have developed regular procedures for detecting and managing this condition.

A regular procedure for screening distress has been continually performed at Kaohsiung Chang Gung Memorial Hospital since December 2014. This program has assisted in caring for and approaching distressed patients. In this study, we intended to ascertain the related factors and prevalence of psychological distress among cancer inpatients in a general hospital. We also aimed to evaluate psychiatric disorders among cancer inpatients with psychological distress.

\section{Patients and methods}

\section{Participants}

This study was conducted as a retrospective chart review in a general hospital in southern Taiwan from December 2014 to May 2015. Our inclusion criteria were as follows: 1) newly hospitalized patients with any confirmed cancer and 2) patients with verbal or written communication ability. Exclusion criteria were as follows: 1) patients with impaired consciousness (Glasgow Coma Scale score below 15 points) and 2) patients who had been readmitted and underwent DT and 12-item Chinese Health Questionnaire (CHQ-12) screening within the past 3 months. However, we could not review the patients who were initially excluded from the program. Therefore, we did not compute the overall response rate for all the procedures.

\section{Measurement of psychological symptoms} Distress Thermometer

The DT is a 1-item self-report screening tool for evaluating psychological distress in patients with cancer. ${ }^{15,23,24}$ The DT grades distress levels over the prior week based on a visual analog scale with scores from 0 (indicating no distress) to 10 (indicating extreme distress). The DT has been utilized in diverse populations and its performance has been compared with different self-report symptom scales. ${ }^{14,25,26}$ Scores of 4 or 5 have each been investigated as potential cutoff scores on the DT to show significant distress in different studies. ${ }^{14,24-29}$ According to the Taiwan Psycho-Oncology Society, a cutoff of 5 on the DT possesses the optimal sensitivity and specificity characteristics among Taiwanese cancer patients. ${ }^{30-32}$

\section{2-Item Chinese Health Questionnaire}

The CHQ-12, with cultural sensitivity, is an excellent tool for researching the potential psychiatric morbidity among ethnic Chinese individuals. The CHQ-12 was developed in Taiwan and derived from the 12-item General Health Questionnaire, which is widely used worldwide. ${ }^{33}$ The CHQ-12 is a standardized screening tool and has been used previously in surveys of minor psychiatric morbidity in 3 communities in Taiwan. ${ }^{34}$ It contains a 4-point response scale: $0=$ "not at all" and "same as usual"; $1=$ "rather more than usual" and "much more than usual". It can be used to recognize a patient with a possible minor mental disorder based on a cutoff score above 3 . The weighted validity of this instrument was found to be acceptable. ${ }^{34,35}$

\section{Procedures}

Ethical approval was obtained from the Human Research Ethics Committee of Chang Gung Memorial Hospital which waived the requirement to obtain patient's consent as all the data assessed in this study were collected from our regular clinical care to which the patients have already agreed. A 5-stage procedure was utilized (Figure 1).

\section{Stage I}

The psycho-oncological consultant service was progressively implemented in our general hospital, from the head and neck cancer ward, urologic cancer ward, colorectal cancer ward to other wards. All the nurses at the oncology wards were 


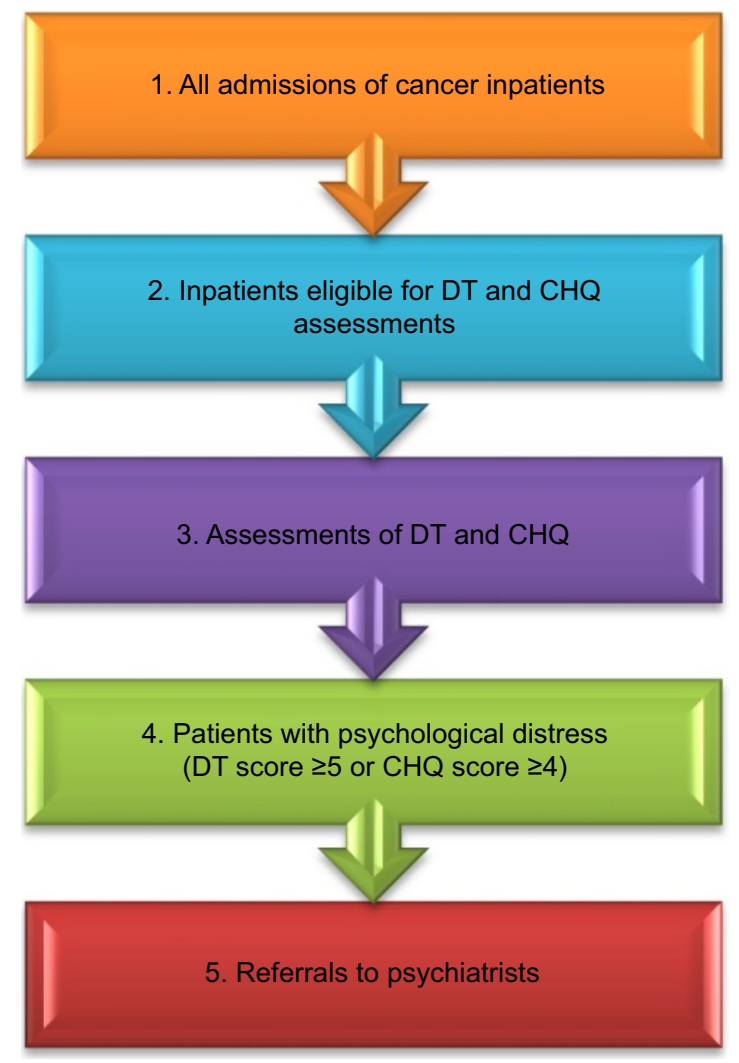

Figure I The cancer psychological consultant service implemented in a general hospital. Abbreviations: $\mathrm{CHQ}$, Chinese Health Questionnaire; DT, Distress Thermometer.

required to attend a 120-minute training course given by the program investigators according to the hospital policy. The psychologist taught the nurses how to use the standardized questions in the clinical scenarios. These trained staff would then determine who were eligible for the distress screening program (using the inclusion and exclusion criteria described earlier).

\section{Stage 2}

The distress screening tools were assessed before the cancer treatment. Nursing staff at the medical oncology wards routinely provided a distress screening service after explaining the aim and procedure of the program to the eligible patients.

\section{Stage 3}

In our study, a patient with distress was defined as having a score of $\geq 5$ on the DT or a score of $\geq 4$ on the CHQ-12. . $^{35,36}$ Similar to the previous DT studies, ${ }^{14,24,26,29}$ only the visual analog DT itself was evaluated; the companion problem list was skipped.

\section{Stage 4}

The nursing staff's assessment and patient sociodemographic data were entered into the electronic nursing records within 48 hours after admission. Scores $\geq 5$ points on the DT or scores $\geq 4$ points on the CHQ-12, which represent psychological distress, indicated that a psychiatric consultation would be suggested by a pop-up window embedded in the Health Information System of our hospital.

\section{Stage 5}

Based on the screening results and pop-up window's suggestion, the final decision on the referral was made by the in-charge doctor, who evaluated clinical factors, including the patient's preference for a psychiatric referral and their physical condition. Each referred cancer inpatient was assessed at bedside by senior psychiatrists within 24 hours after referrals. Psychiatric diagnoses were made according to the Diagnostic and Statistical Manual of Mental Disorders, 4th Edition, Text Revision. ${ }^{37}$

Sociodemographic data and clinical information based on a medical chart review including the nursing staff's evaluation and physicians' assessment were collected. The sociodemographic variables assessed were age, sex, marital status, employment status, education, and current cigarette, alcohol, and betel nut use. We asked whether the patient currently uses these substances habitually or not. The clinical characteristics were comorbid medical diseases, cancer diagnosis, cancer staging, and cancer treatment (surgery, radiotherapy, chemotherapy, and hormonal therapy) in which the patient had received. Since the stage of leukemia could not be defined, patients with leukemia were excluded when cancer staging was investigated. Comorbid medical diseases of patients included hypertension, diabetes mellitus, thyroid disease, heart diseases, respiratory diseases, autoimmune diseases, neurological diseases, etc.

\section{Statistical analysis}

Values are shown as mean \pm SD. We used SPSS version 12.0 (IBM Corporation, Armonk, NY, USA) to analyze descriptive and inferential statistics. Descriptive statistics $\left(\chi^{2}\right.$ and Student's $t$-tests) were executed first to investigate the difference in demographic data and clinical characteristics among the subjects with and without psychological distress. A stepwise forward model of logistic regression was utilized to examine the possible related factors that reach significant levels in univariate analysis, using clinical and demographic data. The significance level was set at $P<0.05$.

\section{Results}

Sociodemographic and clinical characteristics of the participants

Of the 810 study participants, 32 did not complete the CHQ-12 assessments, and $10 \mathrm{did}$ not complete the DT assessments. 
The reasons for incomplete data were unknown. The average age of the patients was $59.4 \pm 13.2$ years. A majority of the participants were male $(73.1 \%)$, married $(88.3 \%)$, educated to a high school or higher level $(65.3 \%)$, and unemployed $(64.9 \%)$. The predominant clinical diagnosis was head and neck cancer (30.7\%), and $44.2 \%$ of the participants were in stage 4 (Table 1). The other cancer types included breast cancer, liver cancer, lung cancer, connective tissue cancer, pancreas cancer, and esophageal cancer (Table 1).

Table I Sociodemographic and clinical characteristics of the participants

\begin{tabular}{|c|c|}
\hline \multirow[t]{2}{*}{ Characteristics } & \multirow{2}{*}{$\begin{array}{l}\text { Total } \\
\mathbf{N}(\%), \mathbf{N}=8 \mathrm{I}\end{array}$} \\
\hline & \\
\hline \multicolumn{2}{|l|}{ Sex } \\
\hline Male & $592(73.1)$ \\
\hline Female & $218(26.9)$ \\
\hline \multicolumn{2}{|l|}{ Age (years) } \\
\hline Mean \pm SD & $59.4 \pm 13.2$ \\
\hline \multicolumn{2}{|l|}{ Education } \\
\hline$\leq 6$ years & $28 I(34.7)$ \\
\hline $7-15$ years & $453(55.9)$ \\
\hline$\geq 16$ years & $76(9.4)$ \\
\hline \multicolumn{2}{|l|}{ Marital status } \\
\hline Married & $715(88.3)$ \\
\hline Employment & $284(35.1)$ \\
\hline Cigarette use & $261(32.2)$ \\
\hline Alcohol use & $205(25.3)$ \\
\hline Betel nut use & $155(19.1)$ \\
\hline \multicolumn{2}{|l|}{ Cancer type } \\
\hline Head and neck & $247(30.7)$ \\
\hline Colorectal & $113(14)$ \\
\hline Urologic & $100(12.3)$ \\
\hline Leukemia & $81(10)$ \\
\hline Others & $267(33)$ \\
\hline Surgery & $726(89.6)$ \\
\hline Radiotherapy & $213(26.3)$ \\
\hline Chemotherapy & $403(49.8)$ \\
\hline \multicolumn{2}{|l|}{ Hormonal therapy } \\
\hline Yes & $3(0.4)$ \\
\hline No & $807(99.6)$ \\
\hline \multicolumn{2}{|c|}{ Comorbid medical disease } \\
\hline 0 & $593(73.2)$ \\
\hline I & $150(18.5)$ \\
\hline 2 & $38(4.7)$ \\
\hline 3 & $20(2.5)$ \\
\hline 4 & $4(0.5)$ \\
\hline 5 & $5(0.6)$ \\
\hline \multicolumn{2}{|l|}{ Stage } \\
\hline 0 & $30(4.3)$ \\
\hline I & $121(17.4)$ \\
\hline 2 & $113(16.3)$ \\
\hline 3 & $123(17.7)$ \\
\hline 4 & $307(44.2)$ \\
\hline DT & $2.57(0-10)$ \\
\hline $\mathrm{CHQ}$ & $1.17(0-12)$ \\
\hline
\end{tabular}

Abbreviations: CHQ, Chinese Health Questionnaire; DT, Distress Thermometer.

\section{Prevalence and related factors of psychological distress among cancer patients}

Of the 810 inpatients, 179 (22.1\%) were designated as having psychological distress. Inpatients with psychological distress were significantly younger compared with elder inpatients $\left(\chi^{2}=16.66, P<0.001\right)$, had a lower educational level compared with having a higher educational level $\left(\chi^{2}=9.06, P=0.011\right)$, had head and neck cancer compared with having other cancers $\left(\chi^{2}=41.05, P<0.001\right)$, and had not received chemotherapy compared with having received chemotherapy $\left(\chi^{2}=9.35, P=0.002\right)$. No significant correlations were determined in the light of sex, marital status, employment status, comorbid other disease, having received surgery, radiotherapy and hormonal therapy, cancer staging, and current cigarette, alcohol, and betel nut use (Table 2). When the significant variables mentioned earlier were investigated with respect to psychological distress utilizing the stepwise forward model of logistic regression, younger age (odds ratio $[\mathrm{OR}]=1.82 ; 95 \% \mathrm{CI}, 1.22-2.71$; $P=0.003)$, having head and neck cancer $(\mathrm{OR}=2.43 ; 95 \%$ CI, 1.71-3.46; $P<0.001)$, and having not received chemotherapy $(\mathrm{OR}=1.58 ; 95 \% \mathrm{CI}, 1.09-2.29 ; P=0.015)$ were ascertained to be 3 significant related factors (Table 3 ).

\section{Categorization of psychiatric disorders among cancer inpatients with significant psychological distress}

Of the 179 inpatients with psychological distress, 123 were not referred to psychiatrists; 56 inpatients $(31.3 \%)$ received a psychiatric assessment and psychiatric diagnosis (Table 4). The diagnoses comprised adjustment disorder $(n=22,39.2 \%)$, major depressive disorder $(n=13,23.2 \%)$, depressive disorder not otherwise specified $(n=6,10.7 \%)$, anxiety disorder not otherwise specified $(n=4,7.1 \%)$, delirium $(n=2,3.6 \%)$, psychotic disorder not otherwise specified $(n=1,1.8 \%)$, and insomnia disorder $(n=1,1.8 \%)$. Seven patients $(12.5 \%)$ did not have a psychiatric diagnosis.

\section{Discussion}

The primary result from our report was that $22.1 \%$ of the cancer patients suffered from psychological distress. The psychological distress in cancer inpatients was significantly associated with younger age, head and neck cancer, and having not received chemotherapy. The most common psychiatric disorder was adjustment disorder, followed by major depressive disorder, depressive disorder not otherwise specified, and anxiety disorder not otherwise specified. So far as we know, this is the first research to investigate the routine 
Table 2 Comparison of sociodemographic and clinical characteristics between patients with and without psychological distress

\begin{tabular}{|c|c|c|c|c|}
\hline \multirow[t]{2}{*}{ Characteristics } & \multirow{2}{*}{$\begin{array}{l}\text { Cancer patients } \\
\text { with distress } \\
\mathbf{N}(\%), \mathbf{N}=179\end{array}$} & \multirow{2}{*}{$\begin{array}{l}\text { Cancer patients } \\
\text { without distress } \\
\mathbf{N}(\%), \mathbf{N}=63 \mathrm{I}\end{array}$} & \multirow[t]{2}{*}{$P$-value } & \multirow[t]{2}{*}{$\begin{array}{l}\chi^{2} / \text { Student's } \\
\text { t-test }\end{array}$} \\
\hline & & & & \\
\hline Sex & & & 0.425 & 0.636 \\
\hline Male & $135(75.4)$ & $457(72.4)$ & & \\
\hline Female & $44(24.6)$ & $174(27.6)$ & & \\
\hline Age (years) & & & $<0.001$ & 16.655 \\
\hline$\leq 50$ & $66(36.9)$ & $138(2 \mid .9)$ & & \\
\hline$>50$ & $113(63.1)$ & $493(78.1)$ & & \\
\hline Education & & & 0.011 & 9.064 \\
\hline$\leq 6$ years & $46(25.7)$ & $235(37.2)$ & & \\
\hline $7-15$ years & II7 (65.4) & $336(53.2)$ & & \\
\hline$>16$ years & $16(8.9)$ & $60(9.5)$ & & \\
\hline Marital status & & & 0.999 & $<0.001$ \\
\hline Married & I58 (88.3) & $557(88.3)$ & & \\
\hline Employment & & & 0.199 & 1.651 \\
\hline Employed & $70(39.1)$ & 214 (33.9) & & \\
\hline Cigarette use & & & 0.674 & 0.177 \\
\hline Yes & $60(33.5)$ & $20 I(31.9)$ & & \\
\hline Alcohol use & & & 0.953 & 0.003 \\
\hline Yes & $45(25.1)$ & $160(25.4)$ & & \\
\hline Betel nut use & & & 0.420 & 0.651 \\
\hline Yes & $38(2 \mid .2)$ & II7 (I8.5) & & \\
\hline Cancer type & & & $<0.001$ & 41.047 \\
\hline Head and neck & $86(48.0)$ & $163(25.8)$ & & \\
\hline Leukemia & $10(5.6)$ & $103(16.3)$ & & \\
\hline Colorectal & $20(11.2)$ & $80(12.7)$ & & \\
\hline Urologic & $7(3.9)$ & $74(11.7)$ & & \\
\hline Others & $56(31.3)$ & $211(33.4)$ & & \\
\hline Surgery & & & 0.477 & 0.507 \\
\hline Yes & 163 (9I.I) & $563(89.2)$ & & \\
\hline Radiotherapy & & & 0.127 & 2.327 \\
\hline Yes & $55(30.7)$ & $158(25.0)$ & & \\
\hline Chemotherapy & & & 0.002 & 9.354 \\
\hline Yes & 71 (39.7) & $332(52.6)$ & & \\
\hline Hormonal therapy & & & 0.638 & 0.221 \\
\hline Yes & $\mathrm{I}(0.6)$ & $2(0.3)$ & & \\
\hline Comorbid medical disease & & & 0.082 & 9.766 \\
\hline 0 & I4I (78.8) & $452(7 \mid .6)$ & & \\
\hline 1 & $29(16.2)$ & $121(19.2)$ & & \\
\hline 2 & $2(I . I)$ & $36(5.7)$ & & \\
\hline 3 & $4(2.2)$ & $16(2.5)$ & & \\
\hline 4 & $2(1.1)$ & $2(0.3)$ & & \\
\hline 5 & $\mathrm{I}(0.6)$ & $4(0.6)$ & & \\
\hline Stage & & & 0.720 & 2.085 \\
\hline 0 & $9(5.3)$ & $24(4.5)$ & & \\
\hline I & $26(15.4)$ & $95(18.0)$ & & \\
\hline 2 & $27(16)$ & $86(16.3)$ & & \\
\hline 3 & $26(15.4)$ & $97(18.4)$ & & \\
\hline 4 & 81 (47.9) & $226(42.8)$ & & \\
\hline DT & & & $<0.001$ & 21.436 \\
\hline $\mathrm{N}=800 *$ mean $\pm \mathrm{SD}$ & $5.67 \pm 2.23$ & $1.73 \pm 1.27$ & & \\
\hline $\mathrm{N}=800 *$ & $139(17.4)$ & $66 I(82.6)$ & & \\
\hline $\mathrm{CHQ}$ & & & $<0.00$ I & 14.317 \\
\hline $\mathrm{N}=778 *$ mean $\pm \mathrm{SD}$ & $3.66 \pm 2.95$ & $0.45 \pm 0.84$ & & \\
\hline $\mathrm{N}=778^{*}$ & $89(11.4)$ & $689(88.6)$ & & \\
\hline
\end{tabular}

Notes: *Of the 810 study participants, 32 did not complete the CHQ- 12 assessments, and 10 did not complete the DT assessments. Abbreviations: CHQ, Chinese Health Questionnaire; DT, Distress Thermometer; SD, standard deviation. 
Table 3 Related factors for psychological distress among cancer inpatients: logistic regression analysis

\begin{tabular}{lllllll}
\hline Item & $\boldsymbol{\beta}$ & SE $(\boldsymbol{\beta})$ & Wald & OR & 95\% CI & $\boldsymbol{P}$-value \\
\hline Age $\leq 50$ years & 0.600 & 0.203 & 8.738 & 1.82 & $1.22-2.71$ & 0.003 \\
Education & 0.258 & 0.357 & 0.524 & 1.30 & $0.64-2.61$ & 0.469 \\
Head and & 0.888 & 0.180 & 24.382 & 2.43 & $1.71-3.46$ & $<0.00 \mathrm{I}$ \\
neck cancer & & & & & & \\
Non-chemotherapy & 0.459 & 0.189 & 5.866 & 1.58 & $1.09-2.29$ & 0.015 \\
\hline
\end{tabular}

Abbreviations: OR, odds ratio; SE, standard error.

screening for psychological distress among Taiwanese cancer inpatients using DT and CHQ.

\section{Prevalence and related factors of psychological distress among cancer patients}

Our finding that $22.1 \%$ of the cancer inpatients had psychological distress was concordant with the previous data reporting that nearly $20 \%-40 \%$ of cancer patients suffered from psychological distress. ${ }^{15,38-42}$ But our result was lower than that in 2 studies on Korean cancer patients ${ }^{21,22}$ and other studies, ${ }^{43,44}$ which found a rate higher than $50 \%$. This variation in prevalence was related mostly to research method (retrospective or prospective study), sample size, ethnicity, diagnostic criteria, and cancer types. In Taiwan, there has been one study on the prevalence of psychological distress among cancer inpatients as recognized by routine screening utilizing the Taiwanese Depression Questionnaire with a cutoff score of $\geq 13,{ }^{45}$ yielding $26.9 \%$ positive screens.

We found that younger age significantly correlated with psychological distress, which was consistent with previous studies. ${ }^{42,46-49}$ The differences based on the life stage revealed that younger patients were inclined to describe psychological distress and need help, nearly 2.1 times more likely than older patients. ${ }^{49} \mathrm{We}$ surmised that the relationship between distress and age is unlikely linear, but is associated with the obligations that emerged in different life phases. It appears that simultaneously working and looking after children

Table 4 Psychiatric diagnoses of cancer inpatients

\begin{tabular}{ll}
\hline Category and diagnosis & $\begin{array}{l}\text { Total } \\
(\mathbf{N}=\mathbf{5 6}) \mathbf{( \% )}\end{array}$ \\
\hline Major depressive disorder & $13(23.2)$ \\
Depressive disorder not otherwise specified & $6(10.7)$ \\
Adjustment disorder & $22(39.2)$ \\
Anxiety disorder not otherwise specified & $4(7.1)$ \\
Delirium & $2(3.6)$ \\
Insomnia disorder & $\mathrm{I}(1.8)$ \\
Psychotic disorder not otherwise specified & $\mathrm{I}(1.8)$ \\
No psychiatric diagnosis & $7(12.5)$ \\
\hline
\end{tabular}

dwelling at home when battling cancer in the meantime, as particularly young and middle-aged patients did, raises the demand for additional care. ${ }^{49}$

Moreover, this study, in line with former reports, ${ }^{39,42}$ revealed that patients with head and neck cancer were more likely to have psychological distress than did those with leukemia, or colorectal or urologic cancer. Dysfunction of speech and articulation and facial disfigurement were the main reasons for the distress that set head and neck cancer patients apart from other cancer patients. ${ }^{50}$

We also demonstrated that patients who had not received chemotherapy significantly correlated with psychological distress. The possible explanations are as follows: first, those having received chemotherapy may have benefited more from the inhibition of disease progress, which would result in low levels of psychological distress. Second, there was a decline in depression, anxiety, and the impact of the adverse effects of chemotherapy in patients with the passing of time because of the acceptance of the diagnosis and management. ${ }^{51-53}$

In a recent study, Kim et $\mathrm{al}^{22}$ examined the prevalence and related factors of psychological distress in recently diagnosed cancer patients at a medical oncology unit in Korea. They demonstrated that a low educational level was related to psychological distress, which supports our finding that lower educational levels were possibly correlated with psychological distress. Possible explanation for the result mentioned earlier is lower educated people might have lower socioeconomic status, and might have more stressful life events and, thus render psychological distress.

\section{Psychiatric disorders among cancer patients with significant psychological distress}

We analyzed the psychiatric disorders among cancer inpatients with significant psychological distress. Past reports have indicated that major depressive disorder and adjustment disorder were prevalent in cancer patients. ${ }^{54-57}$ Approximately $15 \%-20 \%$ of cancer patients with psychiatric disorder were diagnosed with major depressive disorder, $65 \%$ with adjustment disorder, and $\sim 10 \%$ with delirium. ${ }^{54-56,58}$ Our results showed nearly equal percentages of patients with adjustment disorder and depressive disorder, at $39 \%$ and $34 \%$, respectively. This finding implicated that $10 \%-30 \%$ of cancer inpatients have depressive disorder and need psychotropic and psychological combination treatment.

However, the real prevalence may have exceeded those results. We executed psychiatric assessments for nearly one-third of the inpatients who were recognized as having 
psychological distress and consequently referred to a psychiatrist. Previous data revealed that the referral percentage of cancer patients from oncologists to consultation-liaison psychiatrists was 4\%-45\%. ${ }^{22,59-62}$ The possible reasons for the limited referral rate are a low level of psychological awareness among medical doctors, the stigma attached to psychiatric disease by clinicians, and the traditional idea that a clinician's main mission is saving life rather than dealing with psychological distress. We could improve the referral rates through promotion in formal hospital meetings and offering website learning to the physicians. Furthermore, many cancer inpatients have severe psychosocial problems (eg, lack of social support). We could consult the social workers to conduct family interviews to overcome the lack of support.

In this study, we effectively overcame several methodological limitations of previous studies on the DT. The strength of this study was that the sample was larger and more varied in terms of cancer treatment and kinds of cancer than former studies. These advantages should allow a generalization of our results to other groups of patients. Nevertheless, several limitations should be kept in mind when interpreting these data. First, we did not analyze the total response rate for our regular procedures for screening distress because we could not ascertain the total number of patients who were initially excluded from the procedures. Second, our participants were from a general hospital in southern Taiwan, which may make generalization of our results difficult. Third, this was a retrospective study, so we were unable to probe into the patients' psychiatric distress in the course of their cancer disease. Fourth, a number of inpatients with psychological distress were not referred to a psychiatrist, although we attempted to elevate the referral rate many times through promotion in formal hospital meetings and individually encouraging the physicians caring for the patients.

\section{Conclusion}

Our study indicated that cancer inpatients with psychological distress were more likely to be younger, have head and neck cancer, and have not received chemotherapy. The most common psychiatric disorder was adjustment disorder, followed by major depressive disorder. Early detection of psychological distress and prompt psychiatric consultation and management are very important for cancer inpatients.

\section{Acknowledgments}

The authors thank the medical staff at Kaohsiung Chang Gung Memorial Hospital for their continued support and services. This work had no specific funding.

\section{Author contributions}

YJC and YL originally conceived the study and drafted its funding application. All the authors planned, wrote, and edited this article and took joint responsibility for its contents. All the authors contributed to and approved the final report, and YL is the study guarantor. All authors contributed toward data analysis, drafting and critically revising the paper and agree to be accountable for all aspects of the work.

\section{Disclosure}

The authors report no conflicts of interest in this work.

\section{References}

1. National Comprehensive Cancer Network. Clinical Practice Guidelines in Oncology, Distress Management, Version 1. 2016. Available from: https://www.nccn.org/professionals/physician_gls/pdf/distress.pdf. Accessed June 28, 2016

2. Skarstein J, Aass N, Fossa SD, Skovlund E, Dahl AA. Anxiety and depression in cancer patients: relation between the Hospital Anxiety and Depression Scale and the European Organization for Research and Treatment of Cancer Core Quality of Life Questionnaire. J Psychosom Res. 2000;49(1):27-34.

3. Colleoni M, Mandala M, Peruzzotti G, Robertson C, Bredart A, Goldhirsch A. Depression and degree of acceptance of adjuvant cytotoxic drugs. Lancet. 2000;356(9238):1326-1327.

4. Kissane D. Beyond the psychotherapy and survival debate: the challenge of social disparity, depression and treatment adherence in psychosocial cancer care. Psychooncology. 2009;18(1):1-5.

5. Prieto JM, Atala J, Blanch J, et al. Role of depression as a predictor of mortality among cancer patients after stem-cell transplantation. J Clin Oncol. 2005;23(25):6063-6071.

6. Onitilo AA, Nietert PJ, Egede LE. Effect of depression on all-cause mortality in adults with cancer and differential effects by cancer site. Gen Hosp Psychiatry. 2006;28(5):396-402.

7. Schneider S, Moyer A. Depression as a predictor of disease progression and mortality in cancer patients: a meta-analysis. Cancer. 2010; 116(13):3304; author reply 3304-3305.

8. Monahan PO, Champion V, Rawl S, et al. What contributes more strongly to predicting QOL during 1-year recovery from treatment for clinically localized prostate cancer: 4-weeks-post-treatment depressive symptoms or type of treatment? Qual Life Res. 2007;16(3): 399-411.

9. Reich M, Lesur A, Perdrizet-Chevallier C. Depression, quality of life and breast cancer: a review of the literature. Breast Cancer Res Treat. 2008; 110(1):9-17.

10. Rehse B, Pukrop R. Effects of psychosocial interventions on quality of life in adult cancer patients: meta analysis of 37 published controlled outcome studies. Patient Educ Couns. 2003;50(2):179-186.

11. Carlson LE, Bultz BD. Benefits of psychosocial oncology care: improved quality of life and medical cost offset. Health Qual Life Outcomes. 2003;1:8.

12. Bultz BD, Carlson LE. Emotional distress: the sixth vital sign in cancer care. J Clin Oncol. 2005;23(26):6440-6441.

13. National Comprehensive Cancer Network. Distress management. Clinical practice guidelines. J Natl Compr Canc Netw. 2003;1(3): 344-374.

14. Ma X, Zhang J, Zhong W, et al. The diagnostic role of a short screening tool - the distress thermometer: a meta-analysis. Support Care Cancer. 2014;22(7):1741-1755.

15. Schubart JR, Emerich M, Farnan M, Stanley Smith J, Kauffman GL, Kass RB. Screening for psychological distress in surgical breast cancer patients. Ann Surg Oncol. 2014;21(10):3348-3353. 
16. Gao W, Stark D, Bennett MI, Siegert RJ, Murray S, Higginson IJ. Using the 12-item General Health Questionnaire to screen psychological distress from survivorship to end-of-life care: dimensionality and item quality. Psychooncology. 2012;21(9):954-961.

17. Trask PC. Assessment of depression in cancer patients. J Natl Cancer Inst Monogr. 2004;(32):80-92.

18. Vignaroli E, Pace EA, Willey J, Palmer JL, Zhang T, Bruera E. The Edmonton Symptom Assessment System as a screening tool for depression and anxiety. J Palliat Med. 2006;9(2):296-303.

19. Mitchell AJ, Kaar S, Coggan C, Herdman J. Acceptability of common screening methods used to detect distress and related mood disorderspreferences of cancer specialists and non-specialists. Psychooncology. 2008;17(3):226-236.

20. Mitchell AJ, Baker-Glenn EA, Park B, Granger L, Symonds P. Can the distress thermometer be improved by additional mood domains? Part II. What is the optimal combination of Emotion Thermometers? Psychooncology. 2010;19(2):134-140.

21. Shim EJ, Shin YW, Jeon HJ, Hahm BJ. Distress and its correlates in Korean cancer patients: pilot use of the distress thermometer and the problem list. Psychooncology. 2008;17(6):548-555.

22. Kim SJ, Rha SY, Song SK, et al. Prevalence and associated factors of psychological distress among Korean cancer patients. Gen Hosp Psychiatry. 2011;33(3):246-252.

23. Roth AJ, Kornblith AB, Batel-Copel L, Peabody E, Scher HI, Holland JC. Rapid screening for psychologic distress in men with prostate carcinoma: a pilot study. Cancer. 1998;82(10):1904-1908.

24. Donovan KA, Grassi L, McGinty HL, Jacobsen PB. Validation of the distress thermometer worldwide: state of the science. Psychooncology. 2014;23(3):241-250.

25. Jacobsen PB, Donovan KA, Trask PC, et al. Screening for psychologic distress in ambulatory cancer patients. Cancer. 2005;103(7): 1494-1502

26. Boyes A, D'Este C, Carey M, Lecathelinais C, Girgis A. How does the distress thermometer compare to the Hospital Anxiety and Depression Scale for detecting possible cases of psychological morbidity among cancer survivors? Support Care Cancer. 2013;21(1):119-127.

27. Tuinman MA, Gazendam-Donofrio SM, Hoekstra-Weebers JE. Screening and referral for psychosocial distress in oncologic practice: use of the distress thermometer. Cancer. 2008;113(4):870-878.

28. Wang GL, Hsu SH, Feng AC, et al. The HADS and the DT for screening psychosocial distress of cancer patients in Taiwan. Psychooncology. 2011; 20(6):639-646.

29. Recklitis CJ, Blackmon JE, Chang G. Screening young adult cancer survivors for distress with the distress thermometer: comparisons with a structured clinical diagnostic interview. Cancer. 2016;122(2): 296-303.

30. Taiwanese Psycho-Oncology Society. Introduction of Distress Thermometer - Mandarin Version. 2016. Available from: http://www. tpos-society.org/Attache/News/1056.pdf. Accessed August 26, 2016.

31. Lee CY, Chen H-W, Li YC, Tang WR, Fang CK. Suicide prevention in cancer care. J Intern Med Taiwan. 2011;22:335-343.

32. CY C. Relationship among Degree of Psychological Distress, Demoralized Syndrome, Depression and Suicidal Ideation for Patients with Gynecologic Cancer in a Medical Center in Taiwan [MD thesis]. Taiwan: National Taipei University of Nursing and Health Sciences; 2015.

33. Furukawa T, Goldberg DP. Cultural invariance of likelihood ratios for the General Health Questionnaire. Lancet. 1999;353(9152):561-562.

34. Cheng TA. A community study of minor psychiatric morbidity in Taiwan. Psychol Med. 1988;18(4):953-968.

35. Chong MY, Wilkinson G. Validation of 30- and 12-item versions of the Chinese Health Questionnaire (CHQ) in patients admitted for general health screening. Psychol Med. 1989;19(2):495-505.

36. Gessler S, Low J, Daniells E, et al. Screening for distress in cancer patients: is the distress thermometer a valid measure in the UK and does it measure change over time? A prospective validation study. Psychooncology. 2008;17(6):538-547.
37. American Psychiatric Association. Diagnostic and Statistical Manual of Mental Disorders. 4th ed. Washington, DC: American Psychiatric Association; 2000.

38. Stefanek ME, Derogatis LP, Shaw A. Psychological distress among oncology outpatients. Prevalence and severity as measured with the brief symptom inventory. Psychosomatics. 1987;28(10):530-532, 537-539.

39. Zabora J, BrintzenhofeSzoc K, Curbow B, Hooker C, Piantadosi S. The prevalence of psychological distress by cancer site. Psychooncology. 2001;10(1):19-28.

40. Carlson LE, Angen M, Cullum J, et al. High levels of untreated distress and fatigue in cancer patients. Br J Cancer. 2004;90(12):2297-2304.

41. Gao W, Bennett MI, Stark D, Murray S, Higginson IJ. Psychological distress in cancer from survivorship to end of life care: prevalence, associated factors and clinical implications. Eur J Cancer. 2010;46(11): 2036-2044.

42. van Scheppingen C, Schroevers MJ, Smink A, et al. Does screening for distress efficiently uncover meetable unmet needs in cancer patients? Psychooncology. 2011;20(6):655-663.

43. Trask PC, Paterson A, Riba M, et al. Assessment of psychological distress in prospective bone marrow transplant patients. Bone Marrow Transplant. 2002;29(11):917-925.

44. Ozalp E, Cankurtaran ES, Soygur H, Geyik PO, Jacobsen PB. Screening for psychological distress in Turkish cancer patients. Psychooncology. 2007;16(4):304-311.

45. Tu CH, Hsu MC, Chi SC, Lin HY, Yen YC. Routine depression screening and diagnosing strategy for cancer inpatients. Psychooncology. 2014;23(9):1057-1067.

46. Degner LF, Sloan JA. Symptom distress in newly diagnosed ambulatory cancer patients and as a predictor of survival in lung cancer. $J$ Pain Symptom Manage. 1995;10(6):423-431.

47. Gil F, Grassi L, Travado L, Tomamichel M, Gonzalez JR; Southern European Psycho-Oncology Study Group. Use of distress and depression thermometers to measure psychosocial morbidity among southern European cancer patients. Support Care Cancer. 2005;13(8):600-606.

48. Graves KD, Arnold SM, Love CL, Kirsh KL, Moore PG, Passik SD. Distress screening in a multidisciplinary lung cancer clinic: prevalence and predictors of clinically significant distress. Lung Cancer. 2007; 55(2):215-224

49. Tuinman MA, Van Nuenen FM, Hagedoorn M, Hoekstra-Weebers JE. Distress, problems and referral wish of cancer patients: differences according to relationship status and life phase. Psychooncology. 2015; 24(6):699-704.

50. Frampton M. Psychological distress in patients with head and neck cancer: review. Br J Oral Maxillofac Surg. 2001;39(1):67-70.

51. Decat CS, de Araujo TC, Stiles J. Distress levels in patients undergoing chemotherapy in Brazil. Psychooncology. 2011;20(10):1130-1133.

52. Decat Bergerot C, Cavalcanti Ferreira de Araujo TC. Assessment of distress and quality of life of cancer patients over the course of chemotherapy. Invest Educ Enferm. 2014;32(2):216-224.

53. Zhang M, Peng L, Liu W, et al. Physical and psychological predictors of quality of life in Chinese colorectal cancer patients during chemotherapy. Cancer Nurs. 2015;38(4):312-321.

54. Derogatis LR, Morrow GR, Fetting J, et al. The prevalence of psychiatric disorders among cancer patients. JAMA. 1983;249(6):751-757.

55. Massie MJ. Prevalence of depression in patients with cancer. $J$ Natl Cancer Inst Monogr. 2004;(32):57-71.

56. Akechi T, Okuyama T, Sugawara Y, Nakano T, Shima Y, Uchitomi Y. Major depression, adjustment disorders, and post-traumatic stress disorder in terminally ill cancer patients: associated and predictive factors. J Clin Oncol. 2004;22(10):1957-1965.

57. Mitchell AJ, Chan M, Bhatti H, et al. Prevalence of depression, anxiety, and adjustment disorder in oncological, haematological, and palliativecare settings: a meta-analysis of 94 interview-based studies. Lancet Oncol. 2011;12(2):160-174.

58. Hotopf M, Chidgey J, Addington-Hall J, Ly KL. Depression in advanced disease: a systematic review Part 1. Prevalence and case finding. Palliat Med. 2002;16(2):81-97. 
59. Kissane DW, Smith GC. Consultation-liaison psychiatry in an Australian oncology unit. Aust N Z J Psychiatry. 1996;30(3):397-404.

60. McCartney CF, Cahill P, Larson DB, Lyons JS, Wada CY, Pincus HA. Effect of a psychiatric liaison program on consultation rates and on detection of minor psychiatric disorders in cancer patients. Am J Psychiatry. 1989;146(7):898-901.

61. Grassi L, Gritti P, Rigatelli M, Gala C. Psychosocial problems secondary to cancer: an Italian multicentre survey of consultation-liaison psychiatry in oncology. Italian Consultation-Liaison Group. Eur J Cancer. 2000; 36(5):579-585.
62. Shimizu K, Akechi T, Okamura M, et al. Usefulness of the nurse-assisted screening and psychiatric referral program. Cancer. 2005;103(9): 1949-1956.

Neuropsychiatric Disease and Treatment

\section{Publish your work in this journal}

Neuropsychiatric Disease and Treatment is an international, peerreviewed journal of clinical therapeutics and pharmacology focusing on concise rapid reporting of clinical or pre-clinical studies on a range of neuropsychiatric and neurological disorders. This journal is indexed on PubMed Central, the 'PsycINFO' database and CAS, and is the official journal of The International Neuropsychiatric Association (INA). The manuscript management system is completely online and includes a very quick and fair peer-review system, which is all easy to use. Visit http://www.dovepress.com/testimonials.php to read real quotes from published authors.

Submit your manuscript here: http://www.dovepress.com/neuropsychiatric-disease-and-treatment-journal 